\title{
Study on nitrogen removal performance and microbial community structure succession under the condition of anaerobic sludge and low carbon source
}

\author{
Jiabin Wang ${ }^{1, *}$, Tianhang $\mathrm{Li}^{1}{ }^{1}$ Kang $\mathrm{Xie}^{1}$,Cong $\mathrm{Yu}^{1}$, Xiaoyu Wang ${ }^{1}$, and Zeya Wang ${ }^{1}$ \\ ${ }^{1}$ School of Civil Engineering \& Architecture, University of Jinan, NO.336, Nanxinzhuang West Road., Jinan 250022, P.R.China
}

\begin{abstract}
Under anaerobic low carbon source, the reactor was started-up by inoculating anaerobic sludge. The nitrogen removal efficiency and nitrogen conversion pathway during the start-up process were analyzed. At the same time, the structure succession of bacteria in the process of start-up was analyzed by PCR-DGGE technology from molecular biology level. The results showed that inoculated anaerobic sludge had a good effect on nitrogen removal under the condition of anaerobic low carbon source.
\end{abstract}

\section{Introduction}

In recent years, a large amount of nitrogen containing substances produced in the process of production and living have entered the water, causing serious pollution to the water environment due to the development of industry and agriculture and the improvement of the people's living standard[1,2]. The traditional biological nitrogen removal process is to remove nitrogen from the water by ammonification, nitrification and denitrification[3,4]. However, nitrification requires adequate dissolved oxygen, and denitrification requires carbon source, which increased the cost of the wastewater denitrification process [5,6,7]. Therefore, it has attracted wide attention from researchers that how to remove nitrogen economically and efficiently. In this paper, anaerobic sludge was inoculated in a ASBR reactor, and its nitrogen removal characteristics and microbial community structure succession were studied under anaerobic and low carbon source conditions.

\section{Experimental materials and methods}

\subsection{Experimental device method}

The experiment was carried out in a ASBR reactor. The reactor was made of plexiglass. It is $700 \mathrm{~mm}$ high, and the inner diameter is $80 \mathrm{~mm}$, which has the air outlet, the air intake, the water outlet, the water intake. The water quality of the reactor is shown in Table 2.1. In order to remove dissolved oxygen, the inlet is blown to $15 \mathrm{~min}$ by nitrogen. The operation period of the reactor is 48 hours, the settling time is $1 \mathrm{~h}$, and the $3 \mathrm{~L}$ of each cycle needs to be changed. The reactor was stirred by nitrogen circulation and stirred $15 \mathrm{~min}$ per hour. The reactor

\footnotetext{
*Corresponding author: cea_wangjb@ujn.edu.cn
}

avoids light and maintains a constant temperature at 30 degrees by using the temperature controller.

\subsection{Experimental materials}

\subsubsection{Inoculating sludge}

In this experiment, anaerobic sludge from a water treatment plant in Ji'nan was used as inoculate sludge. The sludge concentration in the reactor was controlled at $3000 \pm 50 \mathrm{mg} / \mathrm{L}$.

\subsubsection{Experimental water}

Simulated wastewater is used for experimental water, which is composed of $\mathrm{NH}_{4} \mathrm{Cl}, \mathrm{NaNO}_{2}, \mathrm{KH}_{2} \mathrm{PO}_{4}, \mathrm{MgSO}_{4}$, $7 \mathrm{H}_{2} \mathrm{O}, \mathrm{NaHCO}_{3}$ and $\mathrm{CaCl}_{2} 2 \mathrm{H}_{2} \mathrm{O}$. Trace elements are supplied from garden soil leach solution. Water quality is shown in Table 2.1

Table 2.1 Experimental simulation of wastewater quality

\begin{tabular}{|c|c|}
\hline Index & Range \\
\hline $\mathrm{NH}^{4+}-\mathrm{N}$ & $20-40 \mathrm{mg} / \mathrm{L}$ \\
\hline $\mathrm{NO}^{2}-\mathrm{N}$ & $10-30 \mathrm{mg} / \mathrm{L}$ \\
\hline $\mathrm{TN}$ & $60-130 \mathrm{mg} / \mathrm{L}$ \\
\hline $\mathrm{PH}$ & $7.5-7.9 \mathrm{mg} / \mathrm{L}$ \\
\hline
\end{tabular}

\subsection{Experimental method}

\subsubsection{Conventional index analysis method}

During the experiment, the influent and effluent samples were collected 1 times. The concentrations of ammonia nitrogen, nitrate nitrogen, nitrite nitrogen and total 
nitrogen were analyzed. At the same time, morphological changes of microorganisms at different stages were observed by scanning electron microscope (SEM, Hitachi $\mathrm{S}-2500 \mathrm{C})$. All of the above test methods were carried out according to the national standard method[8].

\subsubsection{Molecular biological analysis method}

In order to clarify the principle of Microbiology in the process of start-up systematically, the microbial population structure and succession law of the sludge were carried out by PCR-DGGE technology for 2 months and 4 months. The sampling sludge was centrifuged for 10 minutes under the condition of $4000 \mathrm{rmp}$, and then the microorganism DNA in the sludge was extracted with the OMEGA DNA Extraction Kit (E.Z.N.A.TM Soil DNA Kit). The DNA was amplified by nested PCR reaction. The first template was diluted 5 times, and the second template was diluted 50 times. The reaction conditions of PCR were as follows: pre-denaturing $5 \mathrm{~min}$ at $94^{\circ} \mathrm{C}$, denaturing $30 \mathrm{~s}$ at $94^{\circ} \mathrm{C}$, annealing $45 \mathrm{~s}$ at $57^{\circ} \mathrm{C}$, refolding $90 \mathrm{~s}$ at $72^{\circ} \mathrm{C}, 32$ cycles, and finally extending $7 \mathrm{~min}$ at $72^{\circ} \mathrm{C}$.

PCR products were analyzed in DGGE by Bio-Rad DcodeTM Universal Mutation Detection System. DGGE adhesive with $16 \mathrm{~mL}$ concentration $35 \%-55 \%$ system. DGGE electrophoresis first runs $5 \mathrm{~min}$ under $120 \mathrm{~V}$ conditions, and then runs $12 \mathrm{~h}$ under $80 \mathrm{~V}$ conditions. After the electrophoresis, Using SDNA-Nucleic Acids Stain Dye (BIO BASIC INC., Canada) to dye $30 \mathrm{~min}$, the strip was cut, and the frozen thawing was repeated for 3 times, and then the DNA was dissolved. The above products were amplified by primers R518 and F357 for PCR, and the purified samples were commissioned in Beijing Huada gene company to be sequenced. The sequencing results were compared on NCBI to determine the microbial population, and Quantity one software was used to analyze the similarity and diversity of the results, and the phylogenetic tree was constructed by Mega5.0 software.

\section{Analysis and discussion of the results}

\subsection{Study on Denitrification performences of anaerobic sludge with low carbon source}

After the ASBR reactor was inoculated with anaerobic sludge, the operation of controlled anaerobic low carbon source has been running for 120 days, and the results are as follows.

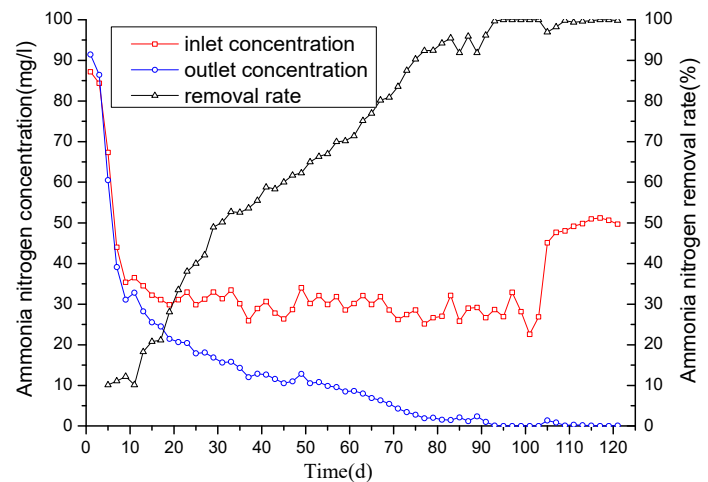

Fig 3.1 The change of ammonia nitrogen in the reactor

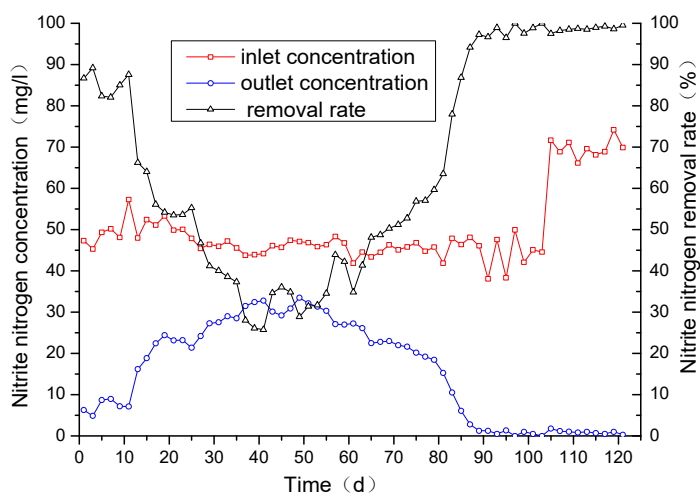

Fig 3.2 The change of nitrite nitrogen in the reactor

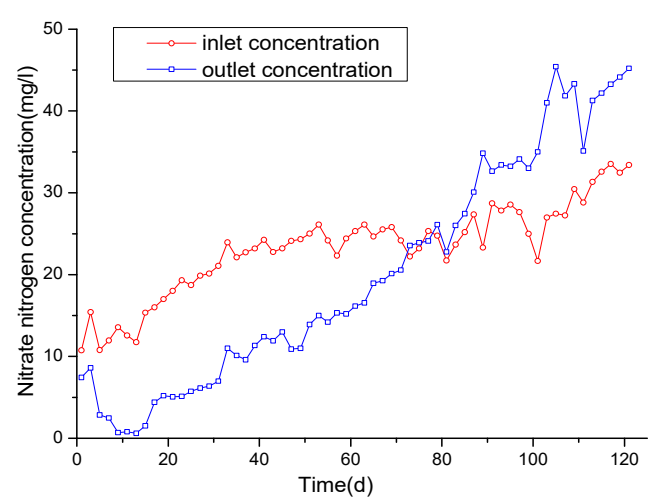

Fig 3.3 The change of nitrate nitrogen in the reactor

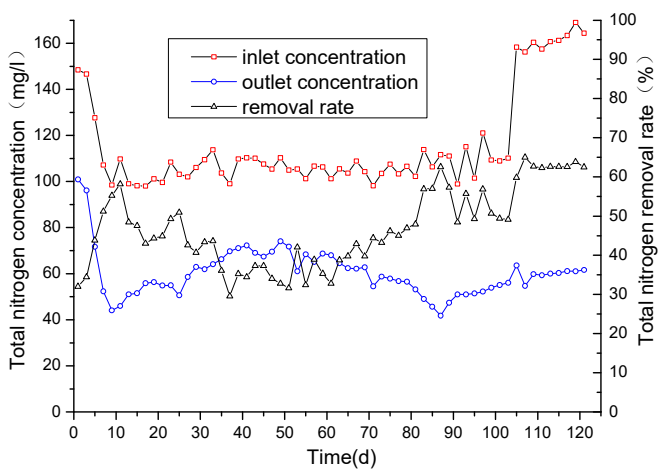

Fig 3.4 The change of total nitrogen in the reactor

As shown in Fig. 3.1-3.4, the changes of $\mathrm{NH}^{4+}$, $\mathrm{NO}^{2-}-\mathrm{N}, \mathrm{NO}^{3-}-\mathrm{N}$ and $\mathrm{TN}$ in reactor are mainly divided into three stages.

At the beginning of the reaction, it cannot adapt to the fragmentation of bacteria in the new environment, 
provide carbon source for denitrifying bacteria, and do not contain dissolved oxygen in the simulated wastewater, and the ammoniation effect is inhibited. The ammonia nitrogen concentration in the effluent is high, and therefore the ammonia nitrogen concentration in the effluent of the reactor is high, and the nitrate nitrogen and nitrite nitrogen concentration in the effluent are low and the total nitrogen removal rate is high. As the reaction goes on, the organic matter in the reactor was degraded gradually. The denitrifying bacteria decreased gradually because of the lack of carbon source. The removal of nitrite and nitrate decreased gradually and the removal rate of total nitrogen was reduced. And at this time, the removal rate of ammonia nitrogen has been increasing, because the new bacterial community that has the effect of removing ammonia nitrogen is enriched in the reactor. In the late reaction, the denitrifying bacteria were gradually replaced by some anaerobes, and the removal rate of ammonia nitrogen, nitrite nitrogen and total nitrogen increased again, reaching stable, while the concentration of nitrate nitrogen in the reactor increased. We can speculate that the dominant population in the late stage of the reactor is an anaerobes that can use ammonia nitrogen and nitrite nitrogen to produce nitrate nitrogen with no additional carbon source.

\subsection{Microorganism population structure and Succession Law}

\subsubsection{Analysis of DGGE Atlas}

The DGGE Atlas of different stages of the reactor is shown in Fig 3.5
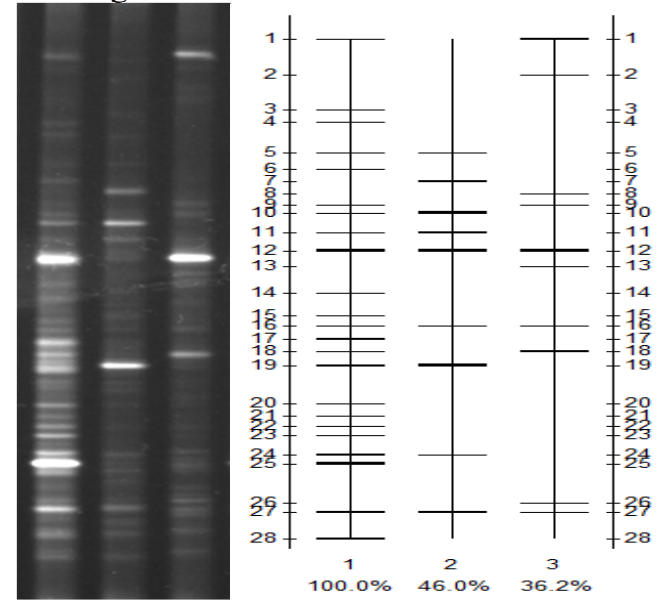

Fig 3.5 DGGE atlas at different stages of the reactor

As can be seen from Fig 3.5, there are obvious differences in the biological population of the reactor at different stages, and the strip of the initial inoculation sludge is obviously more than that of the samples that run for two months and four months. In the DGGE map, the initial dominant population showed more performance. With the reaction goes by, the bands of 3,4 , $14,15,17,18,20,21,22,23,25,28$ were not detected in the follow-up samples. This may be due to the lack of organic matter in the water, resulting in the partial elimination of some heterotrophic microbial populations. At the same time, bands 12 and 16 appeared in all stages of the reactor, indicating that the biological population could survive under anaerobic low carbon environment. Bands 2, 26 and 13 are new bands, which are newly domesticated populations in anaerobic environment. Bands 5, 11, 19, and 24 disappear gradually throughout the operation of the biological system. With the operation of the reactor, these biological populations are gradually eliminated.

\subsubsection{Cluster and diversity analysis in reactor}

Fig. 3.6 is a cluster analysis map of microbial population in different stages of the reactor.

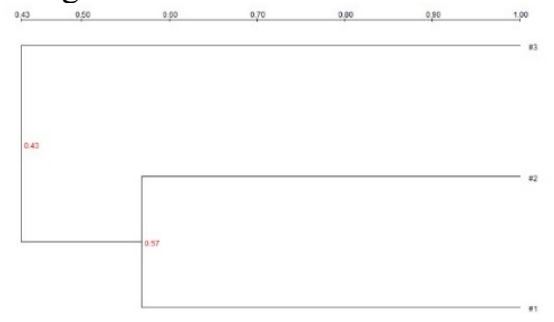

Fig 3.6 Reactor cluster analysis

According to the cluster analysis of microbial population in different stages of the reactor in Fig. 3.6, it is clear that the reactor has obvious biological population succession during operation. The inoculated sludge runs in a completely anaerobic environment. After a long period of operation, some of the sludge's organisms are gradually eliminated, resulting a decline in the number of populations in the system and the similarity index decreased from 0.57 to 0.43 with the increase of running time.

Table 3.1 Diversity analysis of DGGE Atlas of sludge

\begin{tabular}{|c|c|c|c|}
\hline Number & 1 & 2 & 3 \\
\hline Shannon & 3.26 & 2.68 & 2.62 \\
\hline
\end{tabular}

Table 3.1 showed that the diversity index of the reactor decreased significantly after two months of operation, and the Shannon index decreased from 3.26 to 2.68. However, As it continues to run, the diversity index of the biological population changed little. The results showed that some aerobic and heterotrophic bacteria were gradually eliminated during the two months' operation, and the diversity of the biological population in the reactor remained stable.

\subsubsection{Phylogenetic tree analysis of biological population}

Phylogenetic tree was constructed by Mega5.0.

According to the comparison of the results of sequencing on NCBI, we can see that the microbial population in the reactor system is mainly composed of Proteobacteria, and there are a few other microbes. In combination with the DDGE map, some organic and aerobic bacteria are eliminated, such as Fibrobacteres (strip 3), Propionivibrio (strip 4), and Lysobacter (strip 20) gradually eliminated. At the same time, Nitrosomonas (strip 12) and Accumulibacter (strip 16) can be detected at various stages of the reactor. 
According to the comparative literature, it was found that Nitrosomonas belongs to ammoxidation bacteria, and the study showed that Nitrosomonas can show anammox activity under anaerobic conditions ${ }^{[9]}$. Accumulibacter belongs to the anaerobic oxidizing energy bacteria, which exists in the whole stage of biological system operation, indicating that this kind of bacteria has strong impact resistance ${ }^{[10]}$. Bradyrhizobium (band 13) and Panthomonas (strip 26) are a newly acclimated microorganism, in which Bradyrhizobium can use ammonia salt and nitrate as nitrogen source and is another group of nitrogen removal bacteria within the system. Ralstonia (band 5), Rhodospirillum (strip 11), Chitinophagaceae (strip 18) and Conchiformibius (strip 21) keep the advantage for a long time, but they are gradually eliminated with the increase of running time.

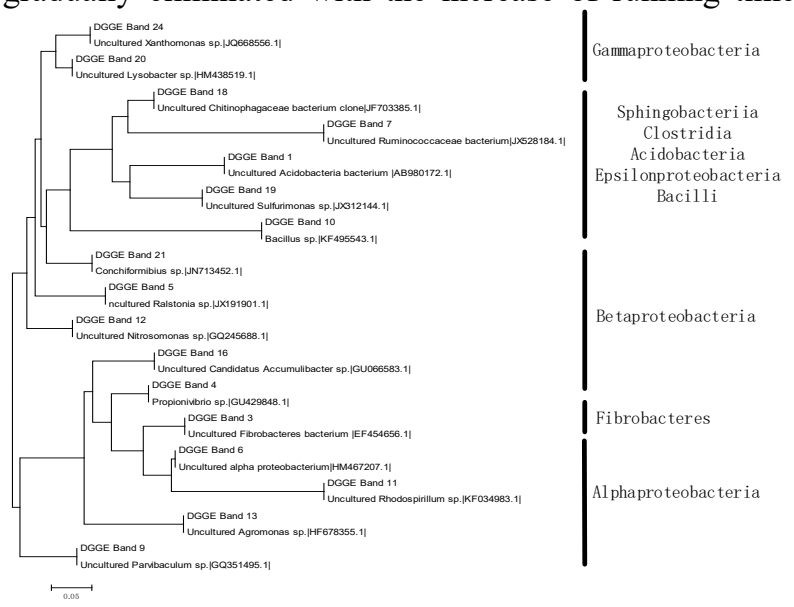

Fig 3.7 Phylogenetic tree of reactor

The main biological systems are $\beta$ - deformable bacteria (Betaproteobacteria) and $\alpha$ - deformia (Alphaproteobacteria), which belong to the deformable bacteria gate (Proteobacteria). With the operation of the reactor, the anaerobic population is the main group, and aerobic and heterotrophic bacteria are gradually eliminated.

\section{Conclusions}

1. The reactor reached stability after running $83 \mathrm{~d}$ under anaerobic low carbon source condition. During the stable operation, the removal rate of ammonia nitrogen and nitrite nitrogen reached $95 \%$, and the total nitrogen removal rate was more than $60 \%$.

2 . The denitrifying bacteria in the reactor were mainly Bradyrhizobium and Nitrosomonas This work was supported by the Higher Education Science and Technology Plan of Shandong Province (J17KA198).

\section{References}

1. People's Republic of China Ministry of environmental protection [A]. Beijing:2010.

2. State environmental protection department. 2015 China Environment Bulletin [EB/OL]. 2015-06-05.

3. Zheng Xingchan, Li Yaxin. Technology of denitrification and phosphorus removal in sewage
[M].Beijing: Chinese architecture Publishing House, 1998:123-128

4. Allgeieeer R J, Peterson W H, Juday C, et al. The anaerobic fermentation of lake deposits[J],2007,Internatuonal Review of Hydrobiology.26(5-6),444-661.

5. Li Jun, Yang Xiushan, Peng Yongzhen. Microorganism and water treatment engineering [M] Chemical Industry Press,2002.

6. Francien Van Luijn, Paul C M, Boers Lambertus Lijklema. Anoxic N2 fluxes from freshwater sediments in the absence of oxidized nitrogen compounds[J].Water Research,1998,32(2):407-409.

7. Lloyd M,Sarah K,John J,et al.Mechanisms of dinitrogen gas formation in anaerobic lagoons $[\mathrm{J}]$.Advances in Enviromantal Research,2000,4(4):133-139.

8. Method for monitoring and analyzing water and wastewater (Fourth Edition).Beijing: China Environmental Science Press,2005.

9. Yang J C, Zhang L, Fukuzaki, et al.High-rate nitrogen removal by the Anammox process with a sufficient inorganic carbon source[J].Biore-source Technology,2010,101:9471-9478.

10. Wang Hong. Research on the efficiency and mechanism for intensification of Bio- substrate in Subsurface Wastewater Infiltration system [D]. Jiangxi University of Science and Technology, 